\title{
Leitura e produção de textos: teorias e práticas na sala de aula - uma revisão do panorama
}

\section{Rita Maria Diniz Zozzoli}

Professora do Curso de Graduaçāo em Letras e do Programa de Pós-Graduação en Letras da FALEUniversidade Federal de Alagoas. É lider do grupo Ensino e aprendizagem de linguas, cadastrado no Diretório do CNPq, e desenvolveu a pesquisa Autonomia relativa na produçāo em diferentes contextos de ensino. financiada com auxilio do $\mathrm{CNPq}$. no periodo de 2007 a 2009.

Fesumo: Numa revisāo de um artigo editado em 1998, pela revista Leitura, o presente trabalho objetiwa examinar propostas teóricas sobre leitura e produção de textos, mais frequentes no ensino e na aprendizagem de línguas, articulandoas às visoes de iinguaring uagem e de sujeito encontradas nessas teorias, relacionando essa discussão à reflexão sobre as práticas observadas em situaçōes de pesquișa em sala de aula. Nesses comentátios, considerando a inter-relaçāo dos conhecimentos sobre o tema em questāo e a interdependêsicia das relaçóes entre teoria e prática, pretende-se uitrapassar una postura de propostas teóricas acabadas que explicariam todos os fenòmenos relacionados ao tema, enfatizandose a complementaridade das visōes, tendo em vista a complexidade dos fenómenos eśtudados na perspectiva da sala de aula de lingua. Procura-se. assim. apresentar ao pesquisador iniciante e ao professor de lingua (materna ou estrangeira) um panorama nāo exaustiwo das questôes em jogo. Palavas-chave: leitura; produçáo: práticas de sala de aula
Résumé: Dans le cadre d'une révision d'um artide publié em 1998 par la rende Lecture, ce texte se propose d'examiner les propositions thériques les plus réquentes sur la lecture et la production de textes, dans le domaine de lenseignement ot de l'apprentissage des langues, en les articulant auju visions de languellangage et sujet présentes daris cos theories, tout en établissant des rapports entre ces considerations et la réllexion sur les praliques obserwes dans les sit.ralions de recherche en salle de dasse de langue. Em onsideérant l'interlace de les connaissances sur le thème en question et linterdépendance des rapports entre théone et pratique. lon envisage daller au-delà des positions thenoniques remes supposément capables dexpliquer tous les phénomenes et lon soutient lidés de la oomplémentarité de ces visions, ompte tenu de la complèxté des phénomènes étuciés dans la perspective de la salle de classe de langua. Ainsi. lion prétend proposer au chercheur débulant et au protesseur de langue (matemelle ou étrangère) un panorama non exaustif des questions en jeu.

Mots-clés: lecture; produrtion; pratiques de salle de classe 


\section{Introdução}

Tema multidisciplinar, a leitura vem sendo, há algumas décadas, objeto de grande número de formalização de propostas teóricas e de realização de investigaçōes em diversas áreas do conhecimento, a tal ponto que se poderia até considerar que há pouco a ser explorado sobre o assunto. Apesar disso, através das observaçōes de pesquisa ${ }^{1}$, da experiência prática em sala de aula e do diálogo com alunos e professores de diferentes graus, este texto parte da constataçāo de que ainda há muito a refletir sobre a questāo, quando se elege a sala de aula como centro da observação dos fenômenos e quando se pretende ir além da visāo de leitura como simples prática escolar.

Quanto à produçào, é relativamente recente a preocupação com a escrita escolar, numa perspectiva em que o aluno seja considerado autor de textos, apesar de o tema da escrita e da reescrita já constarem, há bastante tempo, dos objetivos de formulaçōes teóricas e de pesquisas também simadas em várias áreas do conhecimento. Também não é muito antiga a discussão sobre a necessidade de interligação das práticas de leitura e de escrita na sala de aula, questão ainda menos explorada no quotidiano das situaçōes de ensino e aprendizagem.

Sem objetivar um relato histórico exaustivo, cronologicamente organizado sobre as diversas propostas teóricas e suas implicações nas práticas escolares, buscase neste artigo examinar alguns dos posicionamentos teóricos mais representativos das práticas observadas em situaçōes de pesquisa em sala de aula. Saliente-se que dessas constataçōes não se parte de uma visão dicotômica entre teoria e prática, em que a primeira determinaria as situaçōes de aplicação que funcionariam ou nâo dentro das previsões da perspectiva teórica escolhida, mas de uma visĩo em que as relações entre teoria e prática sāo de interdependência. Aliús, pelo que se observa das situações examinadas, mesmo que se pretenda adotar uma visão teórica determinada a priori, o que se efetiva na prática nunca corresponderá à simples aplicação dessa teoria,
${ }^{2}$ Em 1998, quando da primeira versão deste artigo, a autora coordenava a pesquisa "Leitura e produçào de texto em LM e LE: a constituiçāo de uma gramática do aluno", desenvolvida em equipe, no Grupo de Esnudos Ensino e Aprendizagen de Linguas, do Programa de Pós-Graduaçào em Letras-UFAL, com apoio PIBICCNPq. Recentemente, concluiu a pesquisa "Autonomia relativa na produçào de textos em diferentes contextos de ensine", também desenvolvida en equipe e financiada, no periodo de 2007 a 2009, com awólio do $\mathrm{CNPq}$. 
uma vez que a sala de aula, como afirma Kramsch (1991, p. 8$)^{2}$,

2 Todas as traduçöes dos originais em francês foran feitas pela autora.

${ }^{3}$ Os posicionamentos aqui apresentados limitam-se, sem pretensão de exaustividade, ao campo de estudos da linguagem e da Linguística, nāo contemplando, portanto, outras áreas de conhecimeuto Como a Antropologia, a Filosofia, a História e outras que, nảo obstante, apresentam diversos estudos sabre o tema da Leitura.

+ Existem combinaçōes entre esses tipos básicos compativeis, dependendo da linha de trabalho dos autores, como é o cașn da zrticulação entro as teorias psicolinguisticas, que envolvem os processos mentais a o conhecimento prévio e também os pressupostos da Linguística Textual, por exeluplo.
[...] com sua variedade de "discurso", sua rede complexa de interaçóes entre a professor e o grupo e entre cada um dos membros do grupo, suas relaçōes de força e suas esferas de influẻncia, a multiplicidade de suas intençóes e de suas percepçôes, seus imperativos didáticos e seus compromissos pessoais, é um microcosmo [...].

\section{LEITURA: POSICIONAMENTOS TEÓRICO-PRÁTICOS ${ }^{3}$}

Numa primeira tentativa de análise, num plano bastante amplo e abrangente, constatan-se quatro tipos básicos de posicionamentos teórico-práticost:

1. os que centram a compreensão no sujeito;

2. osquecentram a compreensão na materialidade linguística;

3. os que centram a compreensão na enunciação;

4. os que centram a compreensão nos aspectos histórico-sociais.

Porém, quando se objetiva uma análise mais aprofundada, tal classificação é excessivamente abrangente para dar conta da multiplicidade de propostas teóricas e de cratamentos da questão encontrados em pesquisas e em situaçōes de ensino e aprendizagem, como veremos a seguir.

Partindo do sujeito como categoria central, poderemos ter tanto o subjetivismo idealista criticado por Bakhtin (1981, p. 72-77), que representaria uma visão de leitura como identificação do pensamento do autor, como as propostas mais recentes da Psicolinguística, que, apesar de centradas no sujeito, nāo seguem a mesma visāo. Como ponto comum, constata-se que essas propostas partem de una descrição de fenômenos essencialmente subjetivos. incluindo, no máximo, uma visão interativa centrada no sujeito ou nas relaçōes imediatas entre sujeitos, mesmo quando consideradas mais completas, por envolverem 
o conhecimento prévio do leitor, como o modelo de Rumelhart \&. Ortony ou o de Schank \& Abelson (apud CAVALCANTI, 1989, p. 43-48). Entretanto, é Jecessário reconhecer que, por incluírem noçōes como conhecimento prévio, esses propostas mais recentes, mesmo centradas no sujeito, nào contêm a mesma visão de subjetivismo idealista já citada.

No posicionamento 2, seriam incluídas desde a concepção mais antiga de leitura linear (muito presente ainda nas salas de aula), que enfoca a identificação de unidades linguísticas localizadas na palavra e na frase até as concepçōes estruturalistas mais recentes, as de orientaçāo ckomskyanas, as da Linguística Textual e as pós-estrutukalistas, desde que enfatizem a materialidade linguística. Entretanto, como no caso de 1, é necessário lembrar que as linhas teóricas acima mencionadas representam tendências e estágios distintos da evoluçāo da Linguística. Nāo é possível confundir a visāo linear de bases históricas mais antigas com as visōes nāo lineares mais recentes, como as da Linguística Textual, por exemplo.

No posicionamento 3, estariam os estudos que propōem ultrapassar os limites do linguístico, focalizando a enunciação, dentro dos quais podem ser incluidas, por exemplo, linhas teóricas desde Benveniste até as de seguidores de Culioli, de Ducrot, de Greimas, de Pierce, Austin ou de Searle, ou outros estudos de diversas linhas da semiótica ou da pragmática. Como nos itens anteriores, tais linhas teóricas são muito distintas, o que implica diferenças inclusive na própria visão de enunciação. Por exemplo, Bertrand (in GREIMAS \& COURTÉS, 1986, p. 75 - verbete Énonciation) chama a atenção para as diferenças de conceito de enunciação entre a abordagem lógicosemântica dos fenômenos discursivos de Ducrot, que se fundamenta numa "concepção enunciativa do sentido", e a teoria das "operaçōes enunciativas" de Culioli, que visa à descriçào formal da atividade de linguagem.

No posicionamento 4 , seriam classificadas as tendências sócio-históricas, de origeın marxianas, ligadas à análise do discurso (AD) ou não. Da mesma forma,
: Este último, além disso, prevè a noçāo de crencas. 
- Exemplos de conjugaçăo dos posicionamentos 1 e 2 ; Kintsch \& Van Dijk e Cicurel. aqui se estabelecem diferenças, como, por exemplo, entre seguidores de Pêcheux e Foucault, e outros que se fundamentam principalmente em Bakhtin. A esse respeito, observe-se que a visāo de sujeito assujeitado defendida na maioria das vezes pelos primeiros não é compartilhada nos mesmos termos pelos que trabalham com a visão bakhtinjana (ver visōes de sujeito analisadas mais adiante neste texto).

É óbvio que as tendências insci idas nessa primeira tentativa de classificação reúnem posições muito distintas em suas propostas, por fazerem parte de paradigmas muito diferentes entre si e que não são, portanto, abordáveis em conjunto. Não é possível igualar, num mesmo plano de contribuiçāo para os estudos da linguagem, as visões mais simplistasdecertosposicionamentosavisöesmaiscomplexas e bem formalizadas de propostas da Psicolinguística ou da Linguística Textual, por exemplo. Conclui-se, portanto, que a classificação acima serve principalmente, num primeiro momento, para obter uma visão global da complexidade do tema examinado, considerando-se apenas o foco da compreensão. Num segundo momento, essa classificação será útil para tentar refletir sobre como. na sala de aula, é mais fácil para o professor em processo de formação passar de forma consciente de um visāo teórica para outra dentro do mesmo posicionamento ou dentro de posicionamentos conjugáveis (o $1^{\circ}$ e o $\left.2^{\circ}\right)^{6}$, do que passar para paradigmas opostos (do posicionamento de tipo 1 para o posicionamento de tipo 4, por exemplo). Isto se dá por causa das concepções de língua/linguagem e de sujeito que estão em jogo nos posicionamentos. Essas concepçós, relacionadas a seguir, de forma bastante sucinta, correspondem a raízes ideológicas mais profundas que envolvem as escolhas políticas do professor.

\section{CONCEPÇÕES DE SUJEITO, LINGUAGEM E LEITURA}

A classificação apresentada abaixo, mesmo que nảo leve em conta nuanças e desdobramentos de 
posiçôes, decorrentes da multiplicidade de propostas teóricas existentes, representa uma tentativa de distinguir concepçōes que estão na base de posicionamentos teóricos e práticos encontrados nas situaçōes de sala de aula.

a. concepções de sujeito individualista (ver crítica de Bakhtin ao subjetivismo idealista, em 1981, passim) e de linguagem como expressão do pensamento, que dão origem às visões de leitura como reconhecimento do pensamento do autor, através do reconhecimento (decodificação) de unidades linguísticas isoladas, localizadas na palavra e па frase. Essas unidades linguísticas são reduzidas a uma correspondência com o pensamento;

b. concepções de sujeito racionalista (ver crítica de Bakhtin ao objetivismo abstrato, em 1981, passim) e de língua como objeto isolável para estudo, sem incorporar as imprevisóes do discurso, que dāo origem às visôes de leirura centrada em clementos linguísticos frasais (linguística anterior a Chomsky) ou elementos suprassentenciais ou macrotextuais (linguistica chomskyana e certos escudos da Linguística Textual), ou ainda a visōes de leitura através de estudos psicolinguísticos que seguem essa visão de sujeito racionalista;

c. concepções de sujeito assujeitado pelas determinações histórico-sociais e de linguagem também determinada pelas formaçōes ideológicas e discursivas (Althusser, Foucault e seus seguidores, dentre outros), que estão na base das propostas de leitura que preconizam a completa subordinação da materialidade linguística à sua exterioridade. Muitas vezes. associada a essas visōes, encontra-se, também, 
Tá citadas na introdução deste texto. a concepção de assujeitamento ao inconsciente de base psicanalítica;

d. concepção de sujeito "relacional" (GALISSOT, 1991) ou de sujeito "do conhecimento e da subjetividade" (LANTZ, 1991), dentro de uma teoria que procura conciliar uma teoria social com uma teoria do sujeito. Tal visão de sujeito não assujeitado pelo determinismo racional nem pelo determinisno históricosocial, e que tampouco é individualista, apesar de pouco difundida, é compatível tanto com algumas concepçōes de linguagem oriundas de teorias da enunciação, como com a análise do discurso de linha não foucaultiana. A visāo de linguagem, nesse caso, tanto permite uma conciliação entre a dimensão previsivel (linguagem enquanto regras e categorias organizadas) e a nāo previsivel (representada pelas oscilações discursivas), como a conciliaçào entre a dimensăo psicológica e a dimensão histórico-social (ver definicão de linguagem de MAINGUENEAU, 1995. p. 6). A leitura, consequentemente, poderá ser compreendida, como nas pesquisas coordenadas pela autora deste artigo ${ }^{7}$, como produção de sentidos ao mesmo tempo coletiva e subjetiva. Seguindo o pensamento de Galissot (1991, p. 16), de que a questão de fundo de uma teoria do sujeito é a questâo da autonomia, que esse autor procura definir através da "esperança/utopia de emancipação social e pessoal", as pesquisas ciradas propōem, dentre outros objetivos específicos de cada uma delas, refletir sobre a autonomia do aluno leitor/produtor de textos. 


\section{LEITURA E PRODUÇÃO: \\ UMA VISÃO DE PROCESSO}

Se o processo da leitura for considerado em toda a sua complexidade, dificilmente diferentes perspectivas podem ser desprezadas sem que se obtenha uma redução do fenômeno. É óbvio que as propostas teóricas, sob a alegaçâo de um determinado rigor cientifico, preferem operar recortes e neles procuram se aprofundar. Porém, mesmo diante da impossibilidade de se trabalhar com igual profundidade nas múltiplas facetas do fenômeno, e, diante da necessidade de se operar escolhas paradigmáticas predominantes, convém considerar que estudos que privilegiam uma única perspectiva (seja ela linguística, psicolinguística, enunciativa ou histórico-social) não esgotam uma questão tão complexa, principalmente quando o objetivo é trabalhar o processo como um todo, dentro de uma formaçāo de leitores e produtores de lextos para agir no mundo, para ser cidadãos, através de suas ações. Explicando melhor, trata-se de um processo de natureza complexa dentro de uma situação igualmente complexa, que é a da sala de aula de língua.

\subsection{O processo}

Quanto ao processo de leitura e de produçāo, diante da necessidade de ampliar essa visão, pode-se propor o diagrama apresentado a seguir. Neste diagrama, parte-se da adaptaçăo de alguns conceitos de Coste (1988, p. 15), sem, entretanto, adotar sua concepção de competência comunicativa de leitura e indo mais além no que esse autor considera "componentes dessa competência".

O termo "componentes", de Coste, foi substizido pelo termo elementos no diagrama, uma vez que "componentes" diz respeito a um paradigma que se linitaria à competência de comunicaçăo do sujeito e ao ato imediato de leitura, que não corresponde à visão aqui exposta. Neste diagrama, elenentos não existen apenas em função do leitor e da leitura, mas também em função do autor e da produção; sào, portanto, os elementos que entram en jogo no processo que envolve produçăo 
e leitura. Esse processo se insere tanto numa situaçāo imediata quanto numa dimensão histórico-social mais ampla, como será explicitado mais adiante.

$\hat{E}$ necessário, ainda, esclarecer a terminologia extraída de Coste após as reformulaçōes efetuadas para este trabalho: os elementos de organização textual correspondem à interligação entre os elementos frásticos e transfrásticos; os elementos linguísticos, aos elementos referentes à língua em questão e seu funcionamento; os elementos referenciais, aos elementos do texto relacionados aos domínios de experiência e conhecimento; os elementos relacionais, aos elementos que se referem ao regulamento de trocas interpessoais em função das posiçôes, dos papéis e das intenções dos interlocutores; os elementos situacionais, aos elementos que se referem à situação imediata, às circunstâncias de produção do texto e da leitura.

O diagrama procura visualizar o processo como um todo, compreendendo ao mesmo tempo leitura e produção e inserindo o processo que corresponde à situação mais imediata (circuito menor) dentro de um plano menos imediato e mais amplo, constituído de elementos psicocognitivos e histórico-sociais (circuito maior).

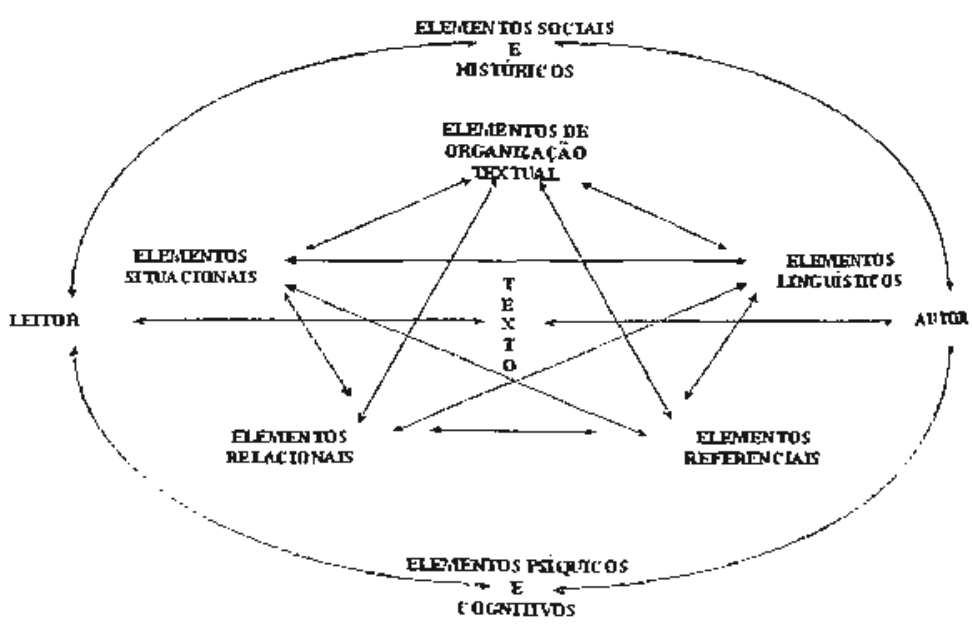

O processo de leitura e produção 


\subsection{A sala de aula}

Quanto à sala de aula de língua, vale salientar que se tem ao mesmo tempo uma situação em que se usa a linguagem para as diferentes trocas dentro da própria situação de aula (Bom dia, professor; prestem atenção, meninos, por exemplo), e também se usa a linguagem como objeto de trabalho, em situaçōes de reflexão ou de simulação, com objetivos de aprendizagem. Cicurel, em Parole sur Parole, em 1985, já explica bem essa dupla utilização da linguagem na sala de aula de língua, dizendo: "o objeto a aprender é a língua, e o meio para chegar a isso é igualmente a língua" (1985, p. 15). Em 1990, a mesma autora explora mais o que chama de "dimensão 'ficcional" da comunicação didática", na qual "para explicar, elucidar o sentido, dar um contexto, os participantes recorrem a situaçōes fictícias" (1990, p. 51).

É claro que na aula de língua estrangeira a "dimensão ficcional" está mais presente, ja pelo próprio fato da "artificialidade" de se falar ou escrever em língua estrangeira em contexto específico para se fazer isso, enquanto que fora dali, essa língua nāo vai ser utilizada ou, quando muito, só vai ser utilizada em determinadas situaçōes. Mas também no caso da língua materna, muitas das práticas mais tradicionais utilizadas em sala de aula tratam essa língua por assim dizer como estrangeira. Essa crítica já Coi feita por Bakhtin (1981, p. 90-109), tanto a respeito do tratamento dado à língua pelas descriçōes linguísticas, como também, em alguns momentos, a respeito desse mesmo tratamento no ensino de línguas.

Para esclarecer melhor, citemos os exemplos de exercícios de gramática ou vocabulário destacados de contextos situacionais. Esses exercícios tanto podem ter como base orientaçōes prescritivas tradicionais, com aplicação explícita de regras da gramática normativa, como podem utilizar a abordagem indutiva dos exercícios estruturais, ou ainda mais recentemente, podem utilizar a abordagem nocional-funcional ou a perspectiva enunciativa. $O$ que eles têm em comum é que desvinculam a lingua de um contexto de uso, o que acarreta apresentá- 
la como objeto a ser decodificado, memorizado. O mesmo acontece na leitura, quando se propōe "decifrar" uп texto apenas através do reconhecimento de unidades linguísticas. Mesmo em lingua materna, e até quando se tenta dar uma dimensão de uso ficcional, muitas vezes esse uso é induzido de forma tão diretiva e tão desvinculada da realidade de fora da sala de aula, contribuindo de qualquer forma para uma ideia de que a língua da escola é outra. diferente da que se utiliza fora dela.

\section{O TRABALHO COM A LEITURA E A PRODUÇÃO DE TEXTOS EM SALA DE AULA}

A relação entre as propostas teóricas e o trabalho com a leitura e a produçăo em saía de aula, como já foi salientado, nāoé de biunivocidade. Entretanto, a influência das visões teóricas é inegável, mesmo quando ela não é estabelecida de forma consciente pelos professores que as utilizam. Quando o professor näo participa de nenhum processo de formação continuada, torna-se muito dificil para ele identificar os diferentes paradigmas e, mais ainda, relacioná-los com sua prática, operando escolhas. Muitas vezes torna-se mais fácil adotar a proposta de um livro didático ou receber alguma receita pronta de algum estágio. É claro que tanto o livro como a receita seguem pressupostos ceóricos que, na maioria das vezes. o professor ou desconhece ou apenas conhece parcial e insuficientemente. Diante dessa dependência de algo pronto, às vezes o professor passa de um posicionamento para outro, em alguns casos até não conciliáveis entre si. Para o processo de aprendizagem, talvez tão prejudicial quanto essa hesitação, é o fato de se acreditar que tal tcoria ou tal abordagem será a panaceia e que sua aplicação garantirá sucesso. Tais atitudes continuam sendo frequentes nas situaçōes de ensino e aprendizagem nos diversos graus.

Os objetivos de atividades com a leitura em sala de aula de língua diferem de acordo com os objetivos de ensino e aprendizagem. Como a visâo de ensino mais comum ainda é a de transmissão de conhecimentos, a 
leitura vai servir muito frequentemente ao objetivo principal dessa transmissão de conhecimentos e de avaliação dessa transmissāo. Servindo a esse duplo objetivo, o que vai variar são os tipos de conhecimentos que serão introduzidos de acordo com as linhas teóricas subjacentes. É interessante observar que a adoçâo de linhas recentes da Linguistica e da Psicolinguistica não implica necessariamente atuałização da abordagem de ensino e que em muitos casos permanece-se fiel ao duplo objetivo acima mencionado (transmissão e avaliaçāo dessa rransmissão).

Geraldi (1984, p. 85 e 1993, p. 173-174) nos fala do pretexto da leirura, levantando a discussāo sobre para quem o pretexto serve (professor ou aluno) e também sobre o tipo de pretexto, que inclusive pode não ser o de transmissão de conteúdo (o texto como pretexto para a produçāo de oucro texto ou para dramatizações, ilustrações, desenhos etc.). Concordando com Geraldi e visando acrescentar uma contribuição para a compreensão da utilização da leitura/ produção de textos na sala de aula, no presente trabalho será feita a distinção entre pretexto, que corresponderá aqui a uma sub-utilização do texto, com objetivo principal (e às vezes único) de transmissāo de algum conteúdo e sua posterior avaliaçāo, e o trabalho de leitura integrado a atividades de reflexāo e de produção. Corn base nessas distinçôes, é possivel destacar:

\subsection{Leitura com o objetivo de transmissão de conteúdos e posterior avaliaçăo/ produção com o objetivo de reproduzir conhecimentos}

Atividades ${ }^{8}$ com o texto ou a partir dele:

\subsubsection{Leitura em voz alta, com observação de correção} de conteúdos fonológicos (pronúncia correta das palavras, com base na pronúncia culta, observância das pausas, do ritmo e da entonação)

Dentro de uma visão de sujeito, de linguagem e de leitura de tipo a ou de tipo b, nas visōes estruturais dos
: O termo atividades tern aqui um significado genérico, abrangendo tanto as avividades mais dinigidas e fechadas, como os exercícios mais tradicionais, como também as atividades menos dirigidas, em que há espaço para a criatividade. Vale ainda salientar que os diferentes tipos de atividades apresentados tanto em 1 como em 2 nāo săo excludentes entre si. 
Perguntas abertas ș̃o aqui compreendidas como aquelas que não sugerem uma única resposta e não remetem a partes do texto já identificáveis na própria pergunta, por exemplo. primórdios da linguística, que favorecem a leitura linear, por se localizarem no plano da palavra e da frase (ver concepçōes já referidas acima), geralmente se pretende que essa tarefa acarretará boa pronúncia e/ou melhor compreensão para o aluno. Quando prcenche o objetivo de avaliação de compreensão do aluno, essa atividade é adequadamente criticada por Kleiman (1993, p. 21-22). É útil observar que, mesmo quando não se objetiva a avaliação da compreensāo, o tratamento dos conteúdos fonológicos por si mesmos, enquanto conteúdos, desvinculados de qualquer outro objetivo de uso da língua, além de dificultar o processo ao aumentar a carga cognitiva, propicia, muitas vezes, problemas afetivos com a leitura (KLEIMAN,1993, P. 21-22).

\subsubsection{Questionários de "compreensão" orais e/ou escritos}

Em muitas situações de sala de aula, tais questionários correspondem a uma visão de leitura como reconhecimento de sentidos e de formas linguísticas. Tal reconhecimento corresponde ao objetivo de "encontrar as ideias do autor", que se postula como sentidos únicos. geralmente já preestabelecidos pelo professor e/ou livro didático, ou então visa-se ao reconhecimento de formas linguísticas consideradas num plano linear. Por isso, a maior parte das perguntas formuladas não sāo abertas $e$ conduzem quase sempre ao tipo de resposta pretendida pelo professor c/ou livro didático. Ao direcionarem dessa forma a compreensão, muitas vezes até apontam os lugares do texto a ser considerados para determinada resposta. Geralmente sc pretende que a tarefa repetida de reconhecimento em vários textos acabe se transformando em conhecimento para o alino.

Essas práticas correspondem às concepçöes de sujeito, linguagem e leitura de tipo a ou de tipo bvisōes estruturalistas que se limitam ao plano da palavra e da frase, como no item anterior. A essas práticas das atividades de tipo 4.1.1. e 4.1.2. subjaz a ideia que De Certeau (1990, p. 261) encontra na ideologia das Luzes 
e denuncia ainda na época atual: "com mais ou menos resistência, o público é moldado pelo escrito (verbal ou icônico), torna-se semelhante ao que recebe, enfim, deixase imprimir pelo texto e como o texto que lhe é imposto". En outras palavras, citando Bakhtin (1981, p. 99), trata-se da compreensão pretendida como ato passivo, "que exclui de antemäo e por princípio qualquer réplica ativa".

Muitos trabalhos já foram feitos para analisar a qualidade de perguntas e respostas desses questionários, mas, para efeito de aprendizagem, além das tipologias, o que parece ser mais significativo é o fato de a pergunta direcionar mais ou menos a compreensâo (perguntas abertas, apenas para insrigar o diálogo correspondem a uma atitude menos autoritária, por exemplo), é o espaço gerado para respostas diferentes e até destoantes, e, principalmente, é a existência de um espaço para perguntas e comentários dos próprios alunos;

\subsubsection{Exercícios de diversas formas ${ }^{10}$, para explorar} conteúdos linguísticos lexicais ou gramaticais encontrados no texto e apresentados em frases, de forma desvinculada de situaçōes de uso, mesmo ficticias

Tais conteúdoss sāo considerados como objeto final da aprendizagem. Da mesma forma que nas atividades anteriores, aposta-se na identificação, repetição e memorizaçāo de conteúdos sob diferentes formas que garantiriam a aprendizagem da língua (concepçōes de sujeito, linguagem e leitura de tipo a e certas visóes estruturalistas contidas em b). É frequente encontrar-se a alegação por parte de professores e/ou de manuais de que esse trabalho com unidades lexicais ou gramaticais "é feito a partir do texto" e não de frases isoladas. Entretanto é necessário alertar para o fato de que o trabalho feito com esses exercicios nāo acontece dentro do texto que é estudado, nem dentro de outros textos apresentados a parrir de um texto de base, nem a partir de textos dos alunos; é realmente um trabalho executado à parte, fora do texto, e mesmo que urilize formas desse texto, essa utilização se dá através de frases ou expressões isoladas.
Os exercicios mais comuns com frases sảo os de precnchimento de lacunas e os de múltipla escolha. Os que pressupōem alguma transformaçāo da frase são menos fre quentes. 
Como já foi observado em parágrafo anterior sobre a sala de aula, tais exercícios podem seguir paradigmas teóricos diversos, desde a visāo prescritivo-normativa até visōes mais recentes, como, por exemplo, semânticoestruturais, corn exercicios que visam à localização de unidades linguisticas na frase (para explicitar melhor, cite-se o caso de exercícios que, através de lacunas ou múltipla escolha, tratam do emprego de vários tipos de artigos em frases soltas), até visôes nocionais/funcionais, com exercícios que enfocam determinada noção, como a quantidade, por exemplo, mas fazem isso também com frases soltas. Uma análise mais aprofundada dos tipos de exercícios, seus objetivos e contribuiçōes para a aprendizagem, incluindo aqueles que seguem linhas teóricas mais recentes, ainda é necessária, pois geralmente as críticas sobre os exercícios visam quase sempre aqueles de gramática dita tradicional e, mais uma vez, não levam em conta que a questão não está apenas na escolha do paradigma teórico, mas também na forma de se trabalhar com a língua em sala de aula. Entretanto, para nāo extrapolar o tema central deste artigo, essa questão não será aqui explorada. Ela já é objeto de outros trabalhos a serem publicados, com foco específico na gramática.

\subsubsection{Atividades com modelos de macroestruturas textuais}

De uso mais recente e decorrente das contribuições da Linguística Textual, tem-se as atividades com modelos de macroestruturas textuais (que, portanto, estão apoiadas em visões teóricas que ultrapassam o nivel da frase, nas concepçōes de sujeito, linguagem e leitura de tipo b). São trabalhos de elaboraçāo de textos a partir de modelos textuais, em que o aluno reproduz a macroestrutura do texto de base. Geralmente, na base dessas atividades, estão as tipologias textuais que orientam sobre as diferenças de macroestrutura. Segundo Péry-Woodley (1993, p. 98-99), talvez a tipologia mais utilizada no ensino de línguas seja aquela originada da retórica, que distingue quatro grandes tipos: narrativo, descritivo, expositivo, argumentativo. Mas 
há grande variedade de tipologias, segundo os diferentes autores que exploram essa questāo (PÉRY-WOODLEY, 1993, p. $94-103)^{11}$. Recentemente, o grande interesse de muitos teóricos e de muitas pesquisas tem se voltado para as tipologias de gênero, largamente utilizadas por livros didáticos, exames e nas aulas de língua materna. Mesmo reconhecendo a contribuição necessária da descrição dos fenômenos relacionados aos gêneros (textuais ou discursivos, segundo a terminologia dos autores), quando a questão se localiza na sala de aula, muitas vezes essas descriçôes e suas tipologias são utilizadas como soluçāo única e resposta ideal para a aprendizagem com textos.

Mais uma vez, é oportuno salientar que nāo é a escolha da linha teórica linguística que garante por si só que o tratamento da questäo em sala de aula se afaste da visão de transmissão de conhecimento. Foram observadas situações de sala de aula ern que os modelos macrotextuais (sejam referentes a tipos texuais ou a gêneros textuais ou do discurso) são usados de forma diretiva: o professor apresenta o modelo a ser seguido e os alunos devem imitá-lo, sern que haja abertura para discussão, nem no momento da apresentação do modelo, nem no momento da execução da atividade, e tampouco na ocasiāo da correção. Essa questão, também por sua relevância, como a apresentada no item anterior, merece ser objeto de trabalho específico.

\subsubsection{Reconhecimento de informaçōes sobre estilos, escolas de época e biografia de autores}

Essa atividade é encontrada em muitas aulas de literatura, mas tambérn em aulas de língua que utilizam o texto literário. É frequente que o texto literário escolhido seja apenas o canônico, ou seja, texto considerado literário pelos padrões da teoria literária e da crítica (L.JOLO, 1988, p. 87-99). Quando a atividade se reduz ao reconhecimento supracitado, sem propiciar outro tipo de experiência com o fenômeno literário, geralmente tem-se como base a mesma ideia subjacente de que tais informações contribuirão para moldar o leitor, como
11 A esse respeito, acrescentem-se, ainda, trabalhos de autores como Adam (2008), Bronckart (1999), dentre muitos outros que escreveram sobre tipos e gêneros texruais ou gêneros discursivos nas últimas décadas. 
já foi mencionado em 5.1.2., com apoio em De Certeau (1990). Consequentemente, tem-se as concepçöes de sujeito, linguagem e leitura de tipo a, aliadas, em alguns casos, a concepções de tipo b, que visam à correçāo formal no plano da palavra e da frase. A diferença, nesse caso, é que não seria apenas a correção da língua o foco principal da "moldagem", mas também o estilo e, ainda, recorrendo mais uma vez a Lajolo (1988, p. 96), a educação do gosto.

Cabe lembrar que a utilização da leitura uitrapassa o âmbito da sala de aula de língua, estando presente nas aulas de todas as disciplinas com menor ou maior frequência. Os tratamentos em geral correspondem a uma visão de leitura como reconhecimento, objetivando a memorização de conteúdos específicos da discipiina, geralmente explorados através do questionário de compreensào supracitado que, nesse caso, dirige a leitura em função desse objetivo de transmissāo de conhecimentos memorizáveis.

\subsection{Leitura integrada à produção e à reflexão sobre a lingua/linguagem}

A diferença básica entre estas atividades e as mencionadas em 4.1 é que o texto não é aqui considerado como mero instrumento de transmissão e avaliação de conteúdos, e que as concepçōes de sujeito, linguagem e leitura correspondem, segundo a postura do professor e as ações executadas em sala de aula, às visóes contidas em ce d.

Atividades com o texto ou a partir dele:

4.2.1. Atividades que incluam a interaçāo entre professor/alunos e alunos entre si, na compreensāo, na produção e na teflexāo sobre a língua ou a linguagem Essas atividades procuram situar a discussäo sobre o texto lido ou produzido, ou sobre questões de língua/ linguagem, de forma nào centrada no professor, que, entretanto, permanece com o papel de orientar e fomentar o debate e fornecer subsídios, quando necessário. Muito 
defendida atualmente pela maior parte das correntes teóricas e por todos os estágios de formaçāo, esse tipo de prática, que é a proposta mais adequada para que se instale uma certa autonomia de leitura e produçāo no aluno, tem encontrado obstáculos na realidade da sala de aula.

Através de observaçōes de pesquisa e de contatos com professores em formação, observa-se que, por um lado, o professor, por sua formação e sua experiência, tem dificuldades em libertar-se de uma postura diretiva e. por outro lado, os alunos, pelas mesmas razões, também têm dificuldade em abandonar a atitude passiva mas confortável em que se encontram. Junto a isso, em certos casos, o número cxcessivo de alunos em cada turma ( 40 ou mais em algumas turmas do ensino público) aumenca os entraves para um trabalho dito interativo. Diante desse contexto, percebe-se que só se conseguirá alguma mudança significativa em grande escala através de uma ampla transformação na instituiçāo escolar como um todo, incluindo necessária e prioritariamente a formação continuada de professores e do quadro técnico-administrativo, sem falar na reformulaçāo de toda a concepção de currículo, programas, materiais pedagógicos, avaliaçāo (na qual estão incluidos os concursos, como o vestibular, por exemplo, que em muitos casos continuam apenas medindo a memorizaçăo de conteúdos), entre outros.

4.2.2. Atividades que estabeleçam interligação da sala de aula com o contexto social mais imediato (da escola) e o mais amplo (de fora da escola: da comunidade, do bairro, da cidade, do país, do mundo)

Geraldi (1993, p. 16) alerta para a necessidade de produzir "textos na escola e năo para a escola". Tanto a leitura como a produção, na perspectiva de formação do leitor para agir no mundo defendida neste trabalho, devem privilegiar essa interligação com o contexto social. É necessário, entretanto, ponderar que essa ligação com o mundo, quando não executada através de açōes precisas (escrever uma carta reivindicando algo à Prefeitura e 
efetivamente enviar essa carta, por exemplo), pode ser realizada através dos próprios temas e textos escolhidos e produzidos e da discussão que se instala na sala de aula.

A esse respeito, vale considerar que, dentro do contexto escolar, nem sempre é viável tornar todas as produçōes diretamente utilizáveis na realidade de fora da sala de aula ou da escola. A dimensão ficcional, já abordada anteriormente, mesmo quando recusada e negada, de qualquer modo se faz presente, porque é inerente à situação. Pode-se inclusive pretender que ela năo é necessariamente nefasta à aprendizagem. Dependendo do tipo de interaçāo que se instala na sala de aula, a produçāo de um texto literário por um aluno, por exemplo, mesmo que não venha a sair daquele quadro, indo no máximo até o jogral ou o mural da escola, ou mesmo que nem isso aconteça, pode representar para esse aluno uma experiência de interação com os outros sujeitos na sala de aula e uma experiência transformadora em suas perspectivas de ver o mundo e de se expressar diante dele. Essa experiência certamente não poderá ser considerada no mesmo plano que uma produçăo-imitaçăo, imposta e direcionada, obtida em outras circunstâncias.

\subsubsection{Atividades que integrem as modalidades oral e escrita, as habilidades, os gêneros do discurso e também diferenças de variedades linguisticas}

A visão que separa modalidades e habilidades dentro do uso da língua também comumente estabelece hierarquia na aprendizagem. Em língua estrangeira, a hierarquia entre as modalidades (oralidade e escrita) e habilidades (compreensão e expressão) é mais presente $e$ ainda muito adotada nas práticas de sala de aula: primeiro se ouve, depois se fala, em seguida sê lê e por último se escreve. Mesmo em língua materna, ainda é bastante comum aceitar-se a ideia de que é preciso "dominar" a língua (o que geralmente significa falar de acordo com as regras da norma culta) segundo alguns ou, no dizer de outros, atingir determinada "competência linguística", para poder escrever. Marcuschi (1997, p. 41) atesta: "a 
visão monolítica da língua leva a postular um dialeto de fala padrāo calcado na escrita, sem maior atenção para as relaçōes de influências múltiplas ${ }^{12}$ entre fala e escrita".

Nesta nova versão deste artigo, acrescentem-se as discussōes de Marcuschi a es- se respeito em 2001. Segundo esse autor,

$\mathrm{O}$ continuo dos gêneros textuais distingue $\mathbf{e}$ correlaciona os textos de cada modalidade (fala e escrita) quanto às estratégias de formulação que determinam o continuo das caracteristicas que produzem as variaçóes das estruturas textuajsdiscursivas, seleçōes lexicais, estilo, grau de formalidade etc., que se dão num contínuo de variaçōes, surgindo dai semelhanças e diferenças ao longo de contínuos sobrepostos (MARCUSCHI, 2001, p. 42) ${ }^{13}$.

Apesar da distância de uma década entre as formulaçóes e do aprofundamento notável das reflexōes do referido autor, percebe-se, entretanto, nos dados de observaçāo etnográfica das pesquisas supracitadas em língua materna e língua estrangeira, que a sa- la de aula de língua ainda continua muitas vezes separando modalidades e habilidades e, ainda, gêneros discursivos.

Em contexto de intervençăo ou de pesquisa-ação nas pesquisas mencionadas, constata-se que a interligação das modalidades e habilidades e dos gêneros permite vivenciar a língua de forma que ela não se apresente ao aluno como objeto pronto a ser explorado de forma fragmentada; em outras palavras, não seja considerada como "língua morta", como critica Bakhtin. Diz esse autor, quando fala em ensino de LE:

[...] A palavra isolada de seu contexto, inscrita num caderno e apreendida por associação com seu equivalente en russo, toma-se, por assim dizer, sinal, torna-se uma coisa única e, no processo de $i^{2}$ Grifo do autor.

13 Texto do autor em negrito, com expressōes ern itálico aquí reproduzidas. 
compreensão, of fator de reconhecimento adquire um peso muiro forte (BAKHTIN, 1981, p. 95).

$\mathrm{Na}$ mesma visão de "língua morta" criticada por esse autor, se bem que com peso menos forte, porque - aluno já utiliza a língua no seu cotidiano, é possivel estender esse fenômeno do reconhecimento ao ensino de língua materna quando se adota a visão fragmentada dos conteúdos no ensino.

Quanto às variaçöes da língua, muitos autores já falaram sobre a falta de integraçào entre as diversas variedades e a chamada norma culta padrão. Mas ainda é necessário pensar em maneiras de integrar, através de atividades e da própria postura do professor na sala de aula, essa norma padrão e as variedades que os alunos trazem de suas comunidades. Não basta, portanto, reconhecer a diferença, mas é necessário saber como tratá-la nas situaçōes de ensino e aprendizagem.

Falando de plurilinguismo, Dabène (1994, p.153-165) aconselha uma "integração do repertório comunicativo dos alunos" e uma "nova concepção da programação". Suas sugestões, mesmo que destinadas ao ensino plurilíngue, como chegam até ao nivel de atividades, podem servir de exemplo para o tratamento de diferenças de variedades dentro de uma mesma língua. Essa mesma autora chama a atenção para o fato que a escola deve assegurar, para além de uma funçäo puramente pedagógica, uma função de legitimação dos saberes vernaculares que nào deveria limitar-se ao domínio da linguagem, mas estender-se ao conjunto das práticas culturais. Entretanto, a julgar-se pelas práticas observadas em nossas situações de ensino, ainda persiste a legitimação de uma única variedade de prestígio (ainda que dificilmente identificável e identificada), que caminha junto com a legitimação de práticas sociais também consideradas como padrão, correspondentes a classes, grupos sociais e/ou regiōes privilegiados no plano socioeconômico. 


\subsubsection{Atividades que inter-relacionem textos}

considerados literários canônicos com textos literários

nāo canônicos e com texios não literários

Apesar de ainda não se ter efetuado tentativas desse gênero na intervenção da pesquisa, considerase a possibilidade, através de um tema mais ou menos comum e do fenômeno da intertextualidade como um todo, de abordar os tipos de textos acima descritos, tanto em atividades de leitura como de produção. A vantagem de tal abordagem estará provavelmente em facultar a possibilidade de convivência com diferentes tipos de texto em contraste, observando as diferentes relaçôes entre forma, sentido e elementos do discurso. ${ }^{14}$

\subsubsection{Atividades que integram a linguagem verbal e a} linguagem nẫo verbal

Dabène (1994, p. 160) sugere atividades translangagières ${ }^{15}$, que

[...] tẻm por objetivo a aprendizagem da utilização da linguagem através de tarefas nào langagières. mas que requerem, para sua execuçāo, o recurso à linguagem: é possivel suscitar, assim, a realizaçāo de objetos concretos (artiscicos, técnicos ou utilitários), a partir de instruçōes de natureza verbal dadas aos alunos ou produzidas por eles.

Mesmo acatando a sugestāo de Dabène, é preciso ter cuidado para que a integração entre o texto linguistico e o não linguístico possa ser feita de forma que a primazia da linguagem nầ acabe tornando a atividade um exercício de "aplicação de linguagem", em que a realização desses "objetos" passe apenas a existir em função da aprendizagem do item linguístico; ou, então, num movimento inverso. não se tenha uma atividade que termine por quase não trabalhar com as questões referentes à linguagem verbal.

Mais proveitosa ainda para a aprendizagen seria uma abordagem em quc a integraçâo fosse tal que se pudessc partir do não verbal para o verbal e vice-versa.
Para uma visăo mais aprofundada sobre $\circ$ trabalho com o texto likerário na sala de aula, ver Brandāo, 1998.

"Translangagières" e "langapières": o francêss faz diferença entre langagier, da linguagem ("linguageiro"). levando em conra fatores psicológicos, sociológicos, etnológicos erc. (Cf. Dictionnaire de Didactique des Langues), e linguistique (linguistico). Por nào exisrir termo equivalente $e m$ pornuguês, oprou-se por deixá-los em francês neste texto. 
Acrescente-se ainda que, além de "objetos", podem surgir outras alternativas: no domínio das artes, por exemplo, tem-se a produção teatral, a musical, incluindo dança, canto etc.

4.2.6. Atividades que integrem o ensino e a aprendizagem

da língua às outras disciplinas do currículo

Citando Stern, Coste (1995, p.79-93) defende uma concepção curricular mais abrangente para o ensino de línguas segundas, que é o curriculum multidimensional. Esse tipo de currículo ultrapassa os programas nocionaisfuncionais e propōe quatro programas (syllabus) paralelos: um programa de língua, ao mesmo tempo gramatical formal e nocional-funcional; um programa comunicativo/ experiencial, do qual constam as relaçôes motivadas e significantes com o meio físico e social, estabelecidas de forma singular, por meio da comunicação langagière, enquanto compreensão, produção e negociação; um programa de cultura, que adota um ponto de vista antropológico e sociológico; e um programa de formaçāo langagière geral, que corresponde a conhecimentos gerais de linguagem, em très domínios de intervenção: a tomada de consciência linguística, a tomada de consciência cultural e a romada de consciência estratégica. Em seguida, Coste (1995, p. 90) retoma a noção de "código integrado" de Bernstein, oposto ao "código serial". Apesar das críticas, que se devem, segundo Coste, aos excessos de interpretação da proposta de Bernstein, a noção de "código integrado" permite conceber as transversalidades, as passagens entre o que está fora e o que está dentro da escola, como também entre as disciplinas.

Como se pode observar, tal concepção já ultrapassa o quadro do ensino e aprendizagem de línguas e envolve o quadro geral da concepção de currículo escolar global, que passa a ser também multidimensional. Entretanto, cabe salientar que, mais uma vez, o que se observa na prática de nossas instituições escolares é ainda uma concepçă marcada por fronteiras entre saberes e disciplinas, ou então tentarn-se aqui ou ali integraçōes, que muitas vezes 
não ultrapassam a iniciativa de um ou outro professor. Quando efetuadas num plano institucional, essas tentativas sāo ainda pontuais e superficiais, nāo chegando a reformular a ideia de currículo serial, que permanece marcante, mesmo nas instituiçōes mais favorecidas. Portanto, a integração entre os conhecimentos veiculados nas diferentes disciplinas através da leirura e produção de textos é, ainda, um campo a ser explorado, desde que os professores e a escola estejam preparados para executar essa integraçāo, para que ela näo venha apenas significar mais um "modismo", sem muita consequência para a aprendizagem.

\section{REFLEXÕES FINAIS}

Após esse percurso rápido e necessariamente não exaustivo pelas teorias e práticas de leitura e produção de textos, e diante da recusa de recorrer ao receituário, já explicitada na apresentaçāo do número, é descabido apresentar posiçōes conclusivas que remetam a respostas acabadas. $O$ que é possivel concluir após essas considerações, é principalmente a necessidade de se considerar o ensino e a aprendizagem da leitura e da produçāo de textos en sua amplicude, superando as visões fragmentadas e fechadas em determinadas visóes teóricas, ultrapassando o âmbito da sala de aula de lingua, passando por outras disciplinas do currículo e indo além das fronteiras da instituição. Além disso, repetindo o que já vem sendo reivindicado por muitos/as colegas em quase todas as áreas que focalizam de alguma forma o ensino e a aprendizagem, fica evidente a urgência de projetos de formação de professores e de reformulação das propostas institucionais que não se limitem a estágios pontuais de treinamento, para que se supere, nas diversas realidades de sala de aula, o estágio da simples aplicaçâo de propostas teóricas ou de técnicas de ensino. 


\section{Referências}

ADAM, Jean-Michel. Les textes: types et prototypes. Récit, description, argumentation, explication et dialogue. 2.ed. Paris: Armand Colin, 2008.

BAKH'TIN, M. Marxismo e filosofia da linguagem. Sẵo Paulo, Hucitec, 1981.

BRANDĀO, Izabel. Algumas reflexōes sobre o processo de ensino/aprendizagem de linguas e literaturas. Revista Leitura, Maceió, n. 21, p. 35-43, jan./ jun. 1998.

BRONCKART, Jean-Paul. Atividades de linguagem, textos e discursos. Por um interacionismo sócjo-discursivo. São Paulo: EDUC, 1999.

CAVALCANTI, M. Interação lcitor-texto: Aspectos de interpretação pragmática. São Paulo, Editora da UNICAMP, 1989.

CERTEAU, M. de. A invenção do cotidiano. Petrópolis, Vozes, 1996 .

CICUREL, F. Parole sur parole: lc métalangage en classe de langue. Paris, Clé International, 1985.

Lectures interactives cn langue étrangère. Paris,

Hachette, 1991.

COSTE, D. Lccture et compétence de communication. Lc Français dans le Monde, n. 141. Paris, Hachettc/Larousse, p. 25-34, novembre/décembre, 1978.

DABĖNE, L. Repères sociolinguistiques pour l'enseignement des langues. Paris, Hachette, 1994.

GALISSON, R. \& COSTE, D. Dictionnaire de didactique des langues, Paris, Hachette, 1976. 
GALISSOT, R. Au-delà du sujet philosophique et psychanalitique, au-delà du sujet historique: sujet, sujec collectif et théorie sociale. L'Homme et la Société, n. 101. Paris, L'Farmattan, p. 49-55, 1991.

GERALDI, J. W. Portos de Passagem. São Paulo, Martins Fontes, 1991.

GREIMAS, A. J. \& COURTÉs, J. Sémiotique: dictionnajte rajsonné de la théorie du langage. Tome 2. Paris, Hachette, 1986.

KLEIMAN, A. Oficina de leitura: teoria e prática. Campinas, Pontes, 1992.

KRAMSCH, C. Interaction et discours dans la classe de langue. Paris, Hatier/Didier, 1991.

LAJOLO, M. Leitura-literatura: mais do que uma rima, menos do que uma solução. ln: ZILBERMAN, R. \& SILVA, E. T. da (Org.). Leitura: perspectivas interdisciplirares. São Paulo, Árica, 1998.

LANTZ, P. Sujet de la connaissance et de la subjeccivité. L'Honume et la Société, n. 101. Paris, L'Harmatan, p. 49-55, 1991.

MA【NGUENEAU、 D. Les analyses du discours en France.

Présentation. Langages, n. 117. Paris, Laroussse, p. 5-11, mars 1995.

MARCUSCHI, L. A. Concepção de lingua falada nos manuais de português de $1^{\circ}$ e $2^{\circ}$ graus: uma visão crítica. Trabalhos em Lingüistica $\Lambda$ plicada, n. 30. Campinas, Editora da UNICAMP, p.39-79, jul./dez. 1997.

MARCUSCHI, L. A. Da Cala para a escrita. Atividades de retextualização. Sào Paulo: Cortez, 2001.

PE.RY-WOODLEY, M-P. Les écrits dans l'apprentissage: clés pour analyser les productions des apprenants. Paris, Hacherre, 1993.

REVISTA LEITURA. Sala de aula de lingua, Maceió, n. 21. jan./jun. 1998. 